\title{
VOLUMES E LINHAS DE FLUXO DE ATERROS UTILIZANDO MODELOS DIGITAIS DE ELEVAÇÃO E DE TERRENO
}

\section{ARTIGO ORIGINAL}

PETTRES, Roberto ${ }^{1}$

PETTRES, Roberto. Volumes e linhas de fluxo de aterros utilizando modelos digitais de elevação e de terreno. Revista Científica Multidisciplinar Núcleo do Conhecimento. Ano 05, Ed. 08, Vol. 12, pp. 05-19. Agosto de 2020. ISSN: 2448-0959, Link de acesso: https://www.nucleodoconhecimento.com.br/matematica/volumes-elinhas

\section{RESUMO}

Este trabalho apresenta uma formulação matemática para o processamento de dados de aerolevantamento feito com drones na forma de nuvem de pontos do sistema Universal Transversa de Mercator. A formulação faz uso de regressão múltipla, linear e não linear, para o cálculo estimado de volume de aterro e são empregadas curvas e superfícies de nível aos dados de relevo, bem como é apresentado um método iterativo para o cálculo do gradiente para essa superfície, a partir do qual, são traçadas as linhas de fluxo de água em caso de grande precipitação. Os modelos matemáticos, bem como os resultados desse trabalho são apresentados a seguir.

Palavras-Chave: regressão múltipla linear, regressão múltipla não-linear, modelos digital de elevação, modelo digital do terreno, linhas de fluxo.

${ }^{1}$ Doutorado em Métodos Numéricos em Engenharia pela Universidade Federal do Paraná, Mestre em Métodos Numéricos em Engenharia pela Universidade Federal do Paraná, Licenciado em Matemática pela Universidade do Contestado. 


\section{INTRODUÇÃO}

Projetos de engenharia voltados a edificações, construção de reservatórios, rodovias, entre outros, requerem o cálculo de volumes de taludes de corte e aterros. De maneira geral, estes volumes são calculados utilizando dados de levantamentos topográficos. Os trabalhos de movimentação de terra podem ser divididos em duas categorias, faixas longas e estreitas, como é o caso de rodovias e ferrovias e grandes áreas, como reservatórios. Para o cálculo de volumes, para o primeiro caso normalmente são utilizados os métodos baseados em seções transversais, no segundo caso, trabalhase com malhas de pontos ou contorno (volumes calculados através das curvas de nível) (IRVINE, 2005).

Em ambos os casos, medições manuais in loco são necessárias, e, frequentemente adota-se um fator multiplicativo para o valor calculado, o qual, para a maioria das aplicações de engenharia é suficiente, porém, superestimando o volume a partir de um coeficiente que pode variar entre 5 e $25 \%$ a mais do valor real devido ao empolamento (GARCIA e PIEDADE 1984).

Segundo Oliveira e Jesus (2018), para o levantamento topográfico, equipamentos já consagrados, como a Estação Total e o GPS RTK são inquestionáveis quanto a sua acurácia, entretanto, demandam equipes de levantamento e prazo estendido para sua realização.

Cada projeto tem suas próprias características e, segundo elas, apresentam-se limitações de tempo e recursos. A disponibilidade de mão-de-obra qualificada e a metodologia utilizada são fatores chaves para obter-se o êxito do projeto. Em projetos públicos de licitações, onde o projeto básico deve ser confeccionado no menor tempo e orçamento mais enxuto possível, ressalta-se a importância em se refinar e descobrir novos métodos de levantamento topográfico que sejam eficientes e confiáveis.

Com a ampliação do número de aplicações baseadas em aerolevantamento de dados planialtimétricos, pode-se obter resultados com precisão significativa, com economia de tempo e recursos, acompanhamento periódico de execução da obra, além de 
segurança no levantamento dos dados em área de difícil acesso, utilizando-se técnicas de processamento de imagens e modelos matemáticos (OLIVEIRA e JESUS, 2018).

Entre os modelos de processamento de imagens de aerolevantamento, tem-se o Modelo Digital de Elevação (MDE) e do Modelo Digital do Terreno (MDT), os quais utilizam coordenadas cartesianas definindo uma cota $z$ a cada par conjugado de pixels da imagem (PEDREIRA, 2017). A diferença entre estes dois métodos é que no MDT é desconsiderado a vegetação, as edificações e outros objetos sobre o terreno, muito utilizado em aplicações de engenharia, como a geração de curvas de nível, cálculo de volumes de corte e aterro, mapas de drenagem, entre outros (PEDREIRA, 2017).

Entre os modelos matemáticos, diferentes técnicas podem ser consideradas, entre elas, o ajustamento de superfície linear, quadrática ou de grau mais elevado dependendo do número de dados disponíveis e das grandezas que se pretende calcular a partir do modelo. Para o cálculo do volume de corte ou de aterro, o modelo de superfície de regressão múltipla linear, plano, permite uma boa aproximação do relevo real. Para o cálculo dos gradientes da superfície e/ou determinação das linhas de fluxo, a superfície quádrica é mais indicada, pois o vetores não são nem todos paralelos como no caso da superfície linear.

Dessa forma, subsidiar a solução de problemas de engenharia voltados para o cálculo de volumes e/ou outras grandezas constitui a principal motivação e justificativa para realização deste trabalho. Para tanto, a formulação matemática baseia-se em técnicas de regressão múltipla, linear e não linear, cujos dados utilizados na análise de regressão provém do levantamento com drones executado pela equipe de pesquisa do projeto Campus Map[2], realizado pela Universidade Federal do Paraná.

Em tempo, almeja-se com este trabalho, apresentar uma metodologia ou técnica para o ajustamento de superfícies a partir de dados de aerolevantamento, com vista em contribuir com a solução de problemas de engenharia abordados durante a formação e na atuação desse profissional. 


\section{MATERIAIS E MÉTODOS}

O conjunto de dados cartesianos $(x, y, z)$ para análise de regressão múltipla foi gerado a partir de aerolevantamento planialtimétrico (VEIGA, ZANETTI e FAGGION, 2012) e técnicas de processamento de imagens baseadas em fogravimetria. A Figura 1 ilustra uma determinada região do Centro Politécnico da Universidade Federal do Paraná (CPUFPR), apresentada à esquerda como uma imagem de isocores, às quais tons próximos ao vermelho representam maiores elevações, já tons próximo ao azul representam pontos de menor elevação.

Figura 1 - Imagem de elevação com isocores (esquerda) e foto aérea (direita) de parte do CPUFPR.
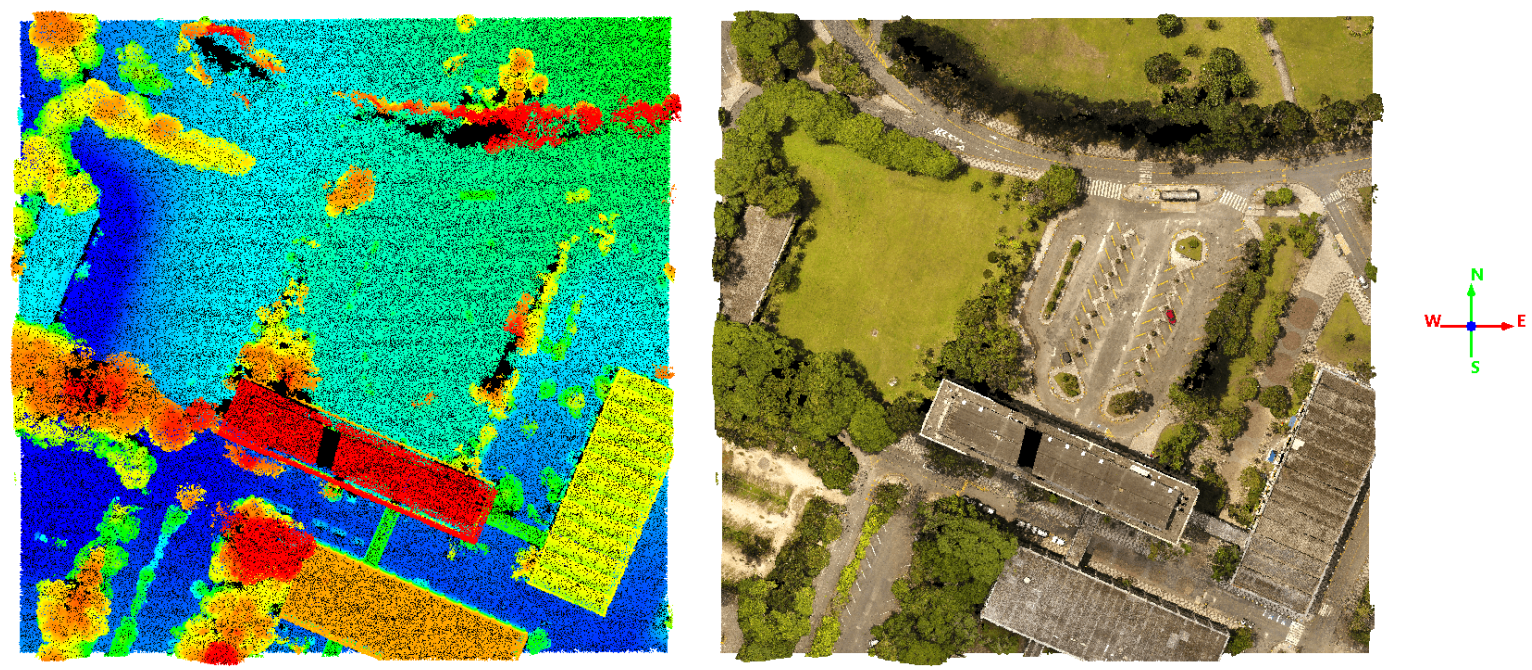

A partir da Figura 1, à direita, foi selecionada uma área poligonal $D$ ilustrada na Figura 2, a qual foi objeto de estudo para o ajustamento de superfície. 
Figura 2 - Área destacada em azul para estudo de regressão múltipla.

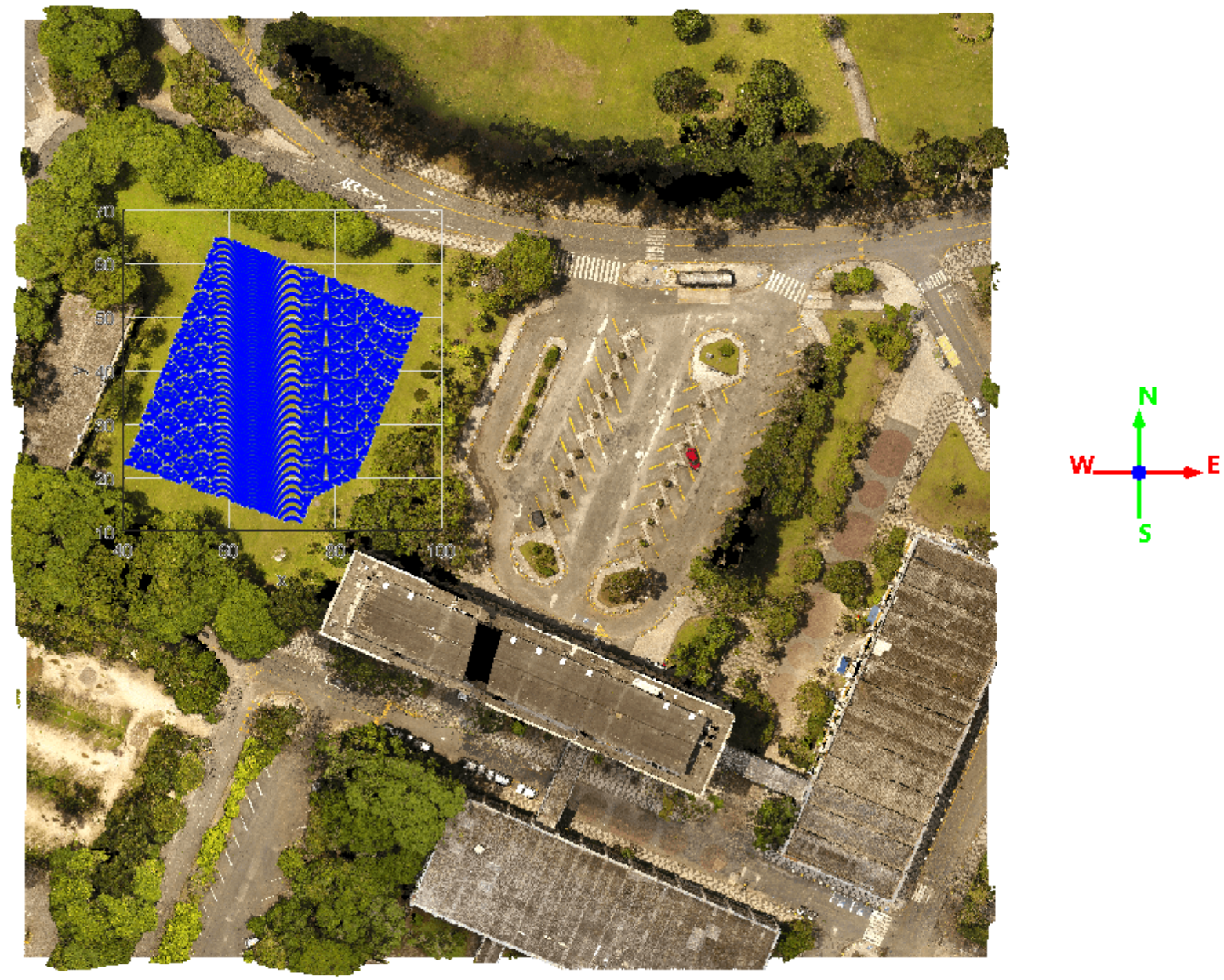

Fonte: O Autor.

Os dados da região em azul tem a forma $(x, y, z)$, onde $x$ e $y$ são coordenadas dadas de acordo com o modelo Universal Transversa de Mercator (UTM) e $z$ são os valores de elevação em relação ao nível do mar. A metodologia para a obtenção da superfície numérica foi desenvolvida no programa computacional MATLAB $15 \AA$ e compreendeu a implementação dos algoritmos de regressão múltipla.

Os valores da componente $z$ da matriz de dados foram são transladados para zero com base no menor valor observado para essa variável considerando-se o plano $(x, y)$ como o limite inferior do aterro. O sistema de equações normais do modelo de regressão múltipla é dado em (1): 


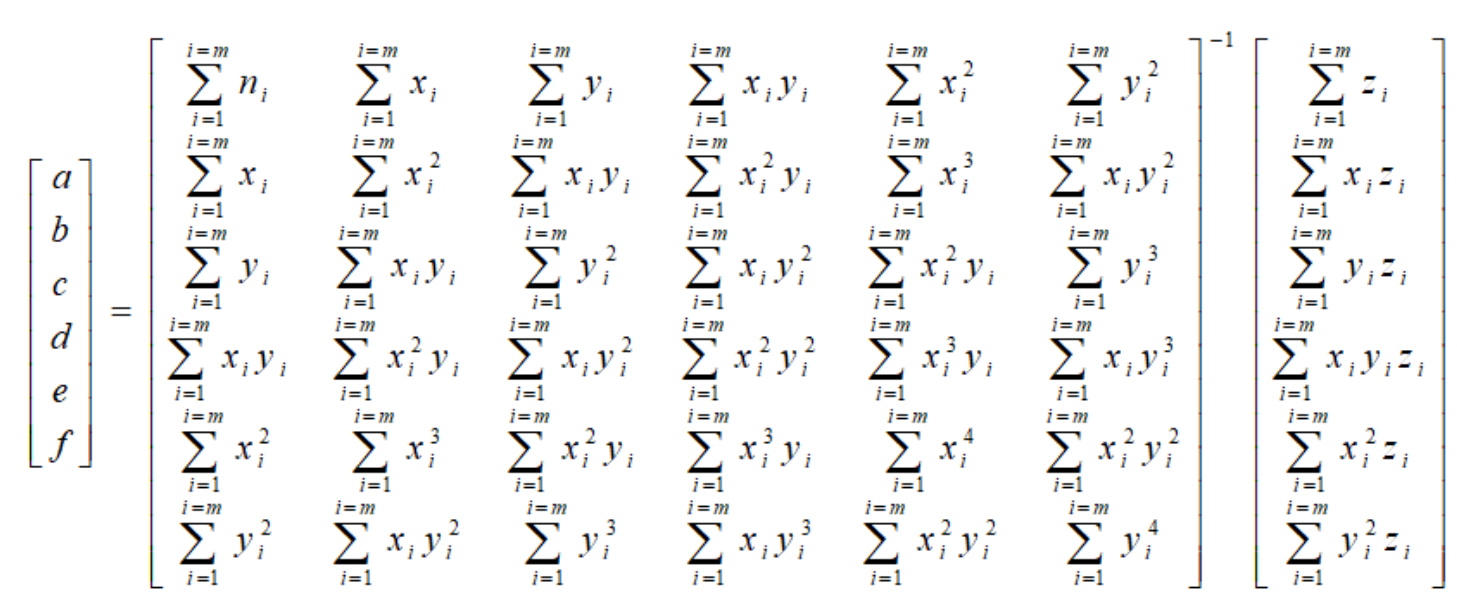

onde $\left(x_{i}, y_{i}, z_{i}\right)$ representa cada ponto do MDT e $a, b, c, d$, e e $f$ são os coeficientes da equação da superfície quádrica que tem a forma

$$
z(x, y)=a+b x+c y+d x y+e x^{2}+f y^{2}
$$

A regressão múltipla utilizada nesse trabalho, linear e não-linear, permite a obtenção de um plano e de uma superfície parabólica, respectivamente, cujo soma dos quadrados das diferenças entre o valor estimado (pontos da superfície numérica) e os dados observados (pontos de elevação do relevo) é mínima, minimizada pela solução do problema de mínimos quadrados.

Para o caso de regressão múltipla linear, $d$, e e $f$ são nulos e tem-se um plano.

\section{MDT E SUPERFÍCIES DE REGRESSÃO}

A Figura 3 ilustra o MDT e as Figura 4 e 5 ilustram a as soluções obtidas para o modelo linear e quadrático de regressão múltipla. 
Figura 3 - Superfície obtida a partir dos dados de levantamento do relevo.

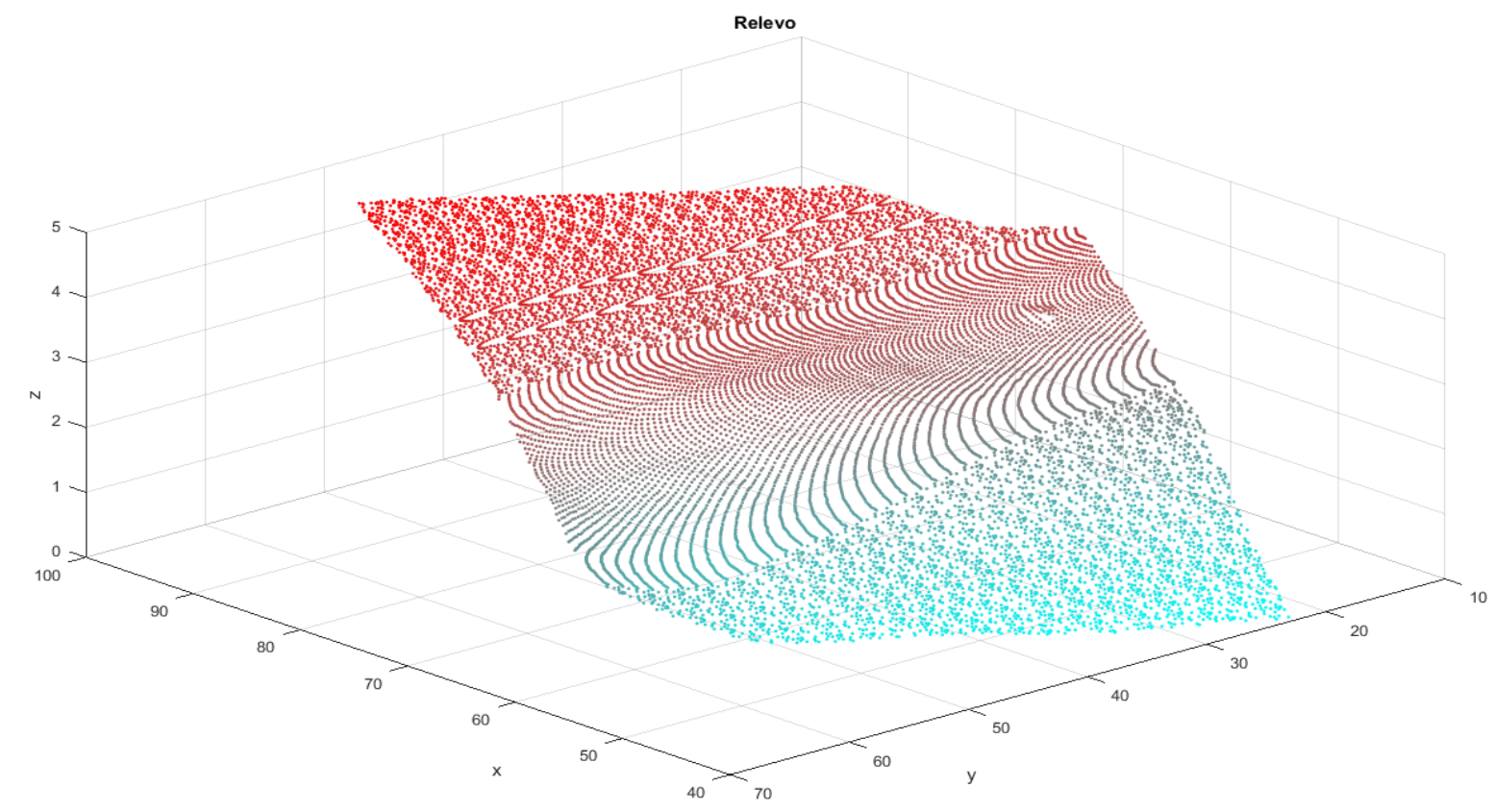

Fonte: O Autor.

Figura 4 - Superfície de regressão linear múltipla para os dados do relevo.

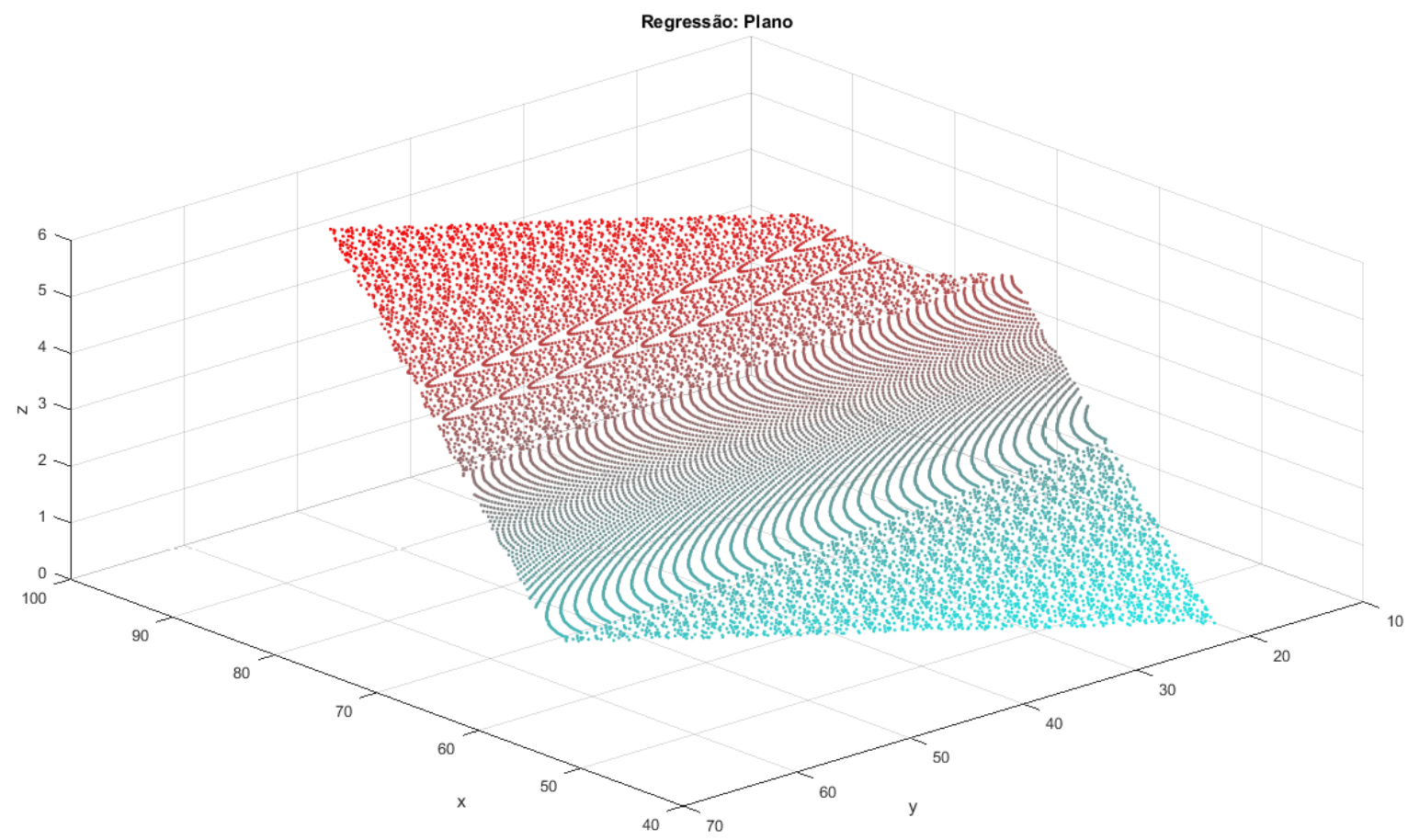

Fonte: O Autor.

RC: 58185

Disponível em: https://www.nucleodoconhecimento.com.br/matematica/volumes-e-linhas 
Figura 5 - Superfície de regressão quadrática múltipla para os dados do relevo.

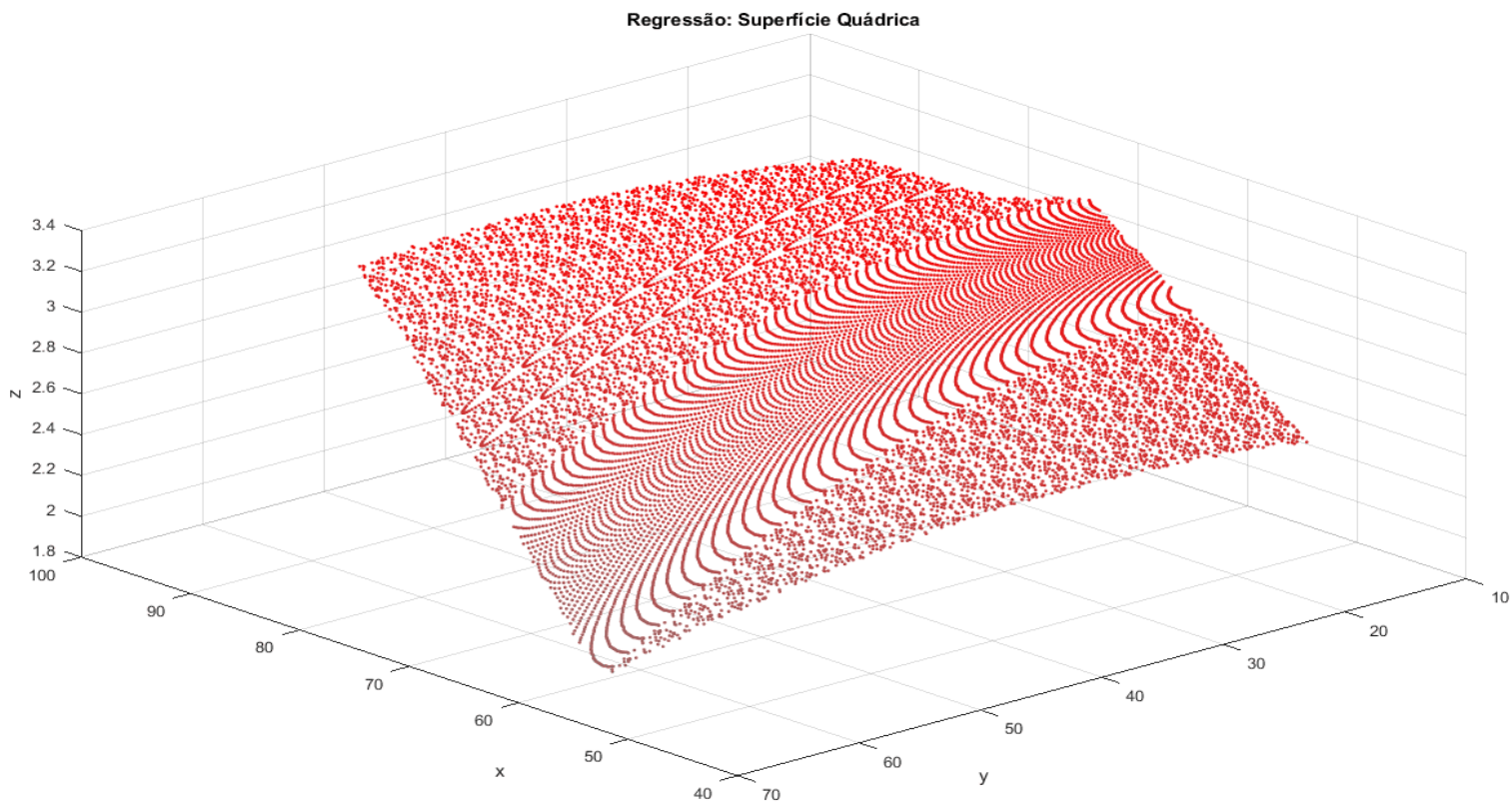

Fonte: O Autor.

Figura 6 - Sobreposição das superfícies obtidas.

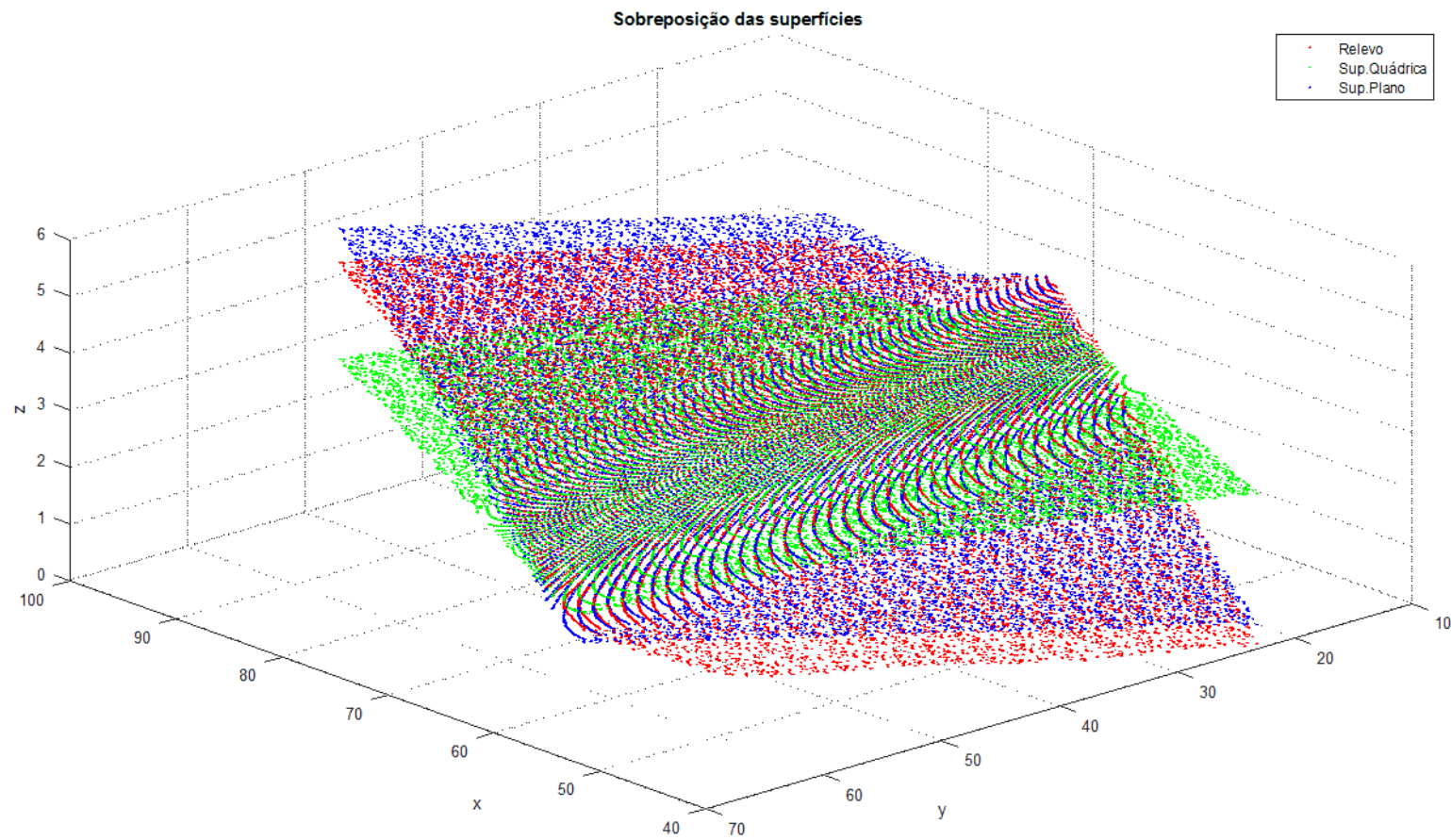

Fonte: O Autor.

RC: 58185

Disponível em: https://www.nucleodoconhecimento.com.br/matematica/volumes-e-linhas 
A Figure 6 ilustra a sobreposição das duas superfícies calculadas, plano e quádrica, em relação aos dados transladados do relevo real. As equações obtidas para o plano de regressão linear, $z(x, y)_{p}$, e superfície quádrica, $z(x, y)_{q}$, são dadas em (3) e (4), respectivamente:

$$
\begin{gathered}
z(x, y)_{p}=-3,19673211+0,09526523 x-0,01357971 \quad y \\
z(x, y)_{q}=2,19414330+0,00979230 x+0,00895871 y+0,00006696 x y+ \\
0,00001321 x^{2}-0,00041386 y^{2}
\end{gathered}
$$

O volume do sólido limitado lateralmente pela fronteira poligonal $D$, inferiormente pelo plano $(x, y)$ e superiormente pela superfície do relevo é igual $5078,491774999969 \mathrm{~m}^{3}$. Os valor obtidos para o volume desse sólido em $\mathrm{m}^{3}$, porém, limitado superiormente pelas superfícies de regressão são:

$$
\begin{aligned}
& \iiint_{D} z(x, y)_{p} d V=5078,4917749994 \\
& \iiint_{D} z(x, y)_{q} d V=5078,4917750002
\end{aligned}
$$

O erro entre o valor real e os valores obtidos em (5) e depois em (6) são de $5,02950570 \times 10^{-10} \mathrm{~m}^{3}$ e $-2,79214873 \times 10^{-10} \mathrm{~m}^{3}$, respectivamente.

\section{CURVAS, SUPERFÍCIES DE NÍVEL E GRADIENTES}

A partir dos dados planialtimétricos, pode-se delimitar as curvas de nível e seções da superfície cuja elevação é a mesma, ou seja, pode-se traçar as superfícies de nível do terreno. 
Figura 7 - Superfície de nível com 10 faixas.

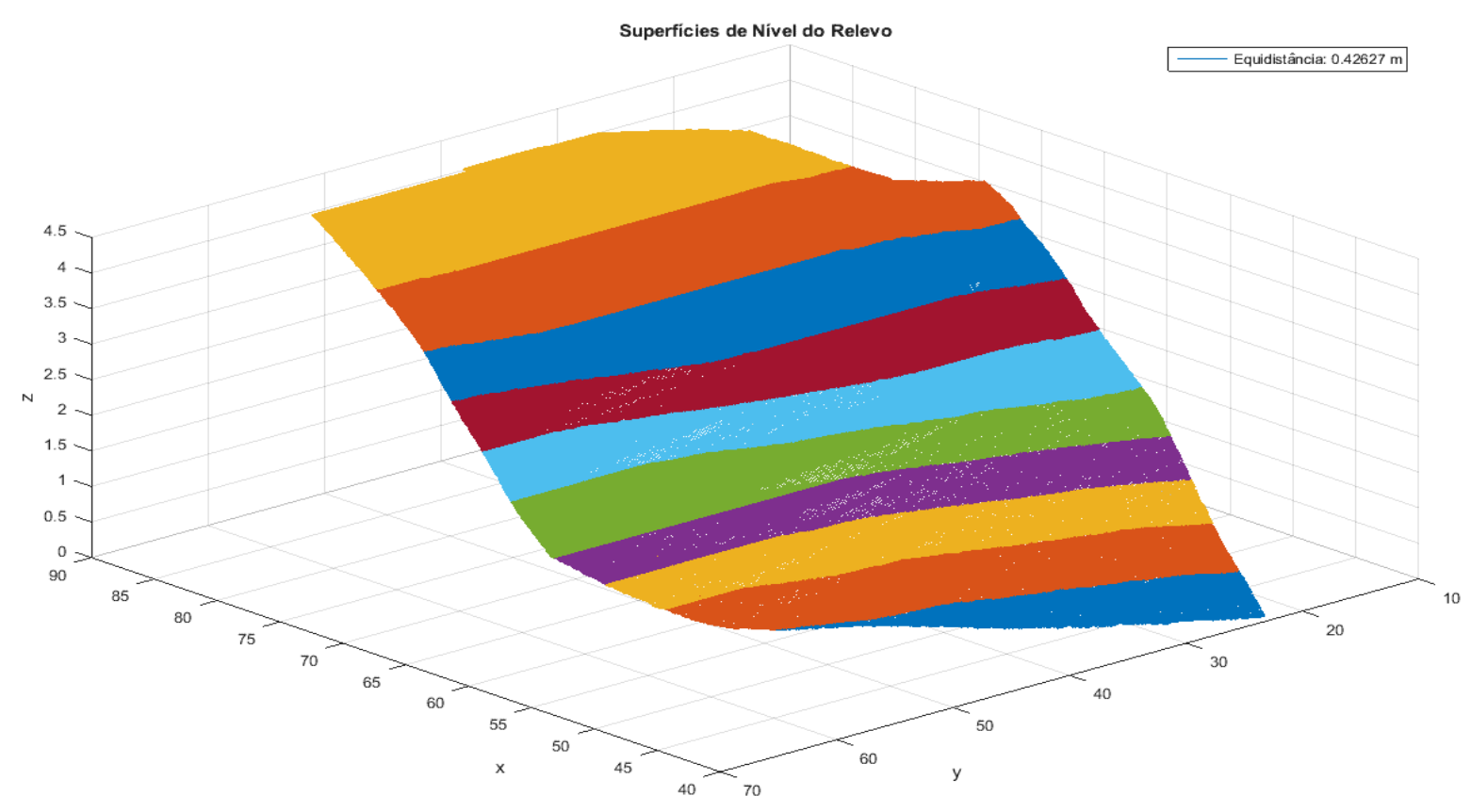

Fonte: O Autor.

Figura 8 - Superfície de nível com 100 faixas.

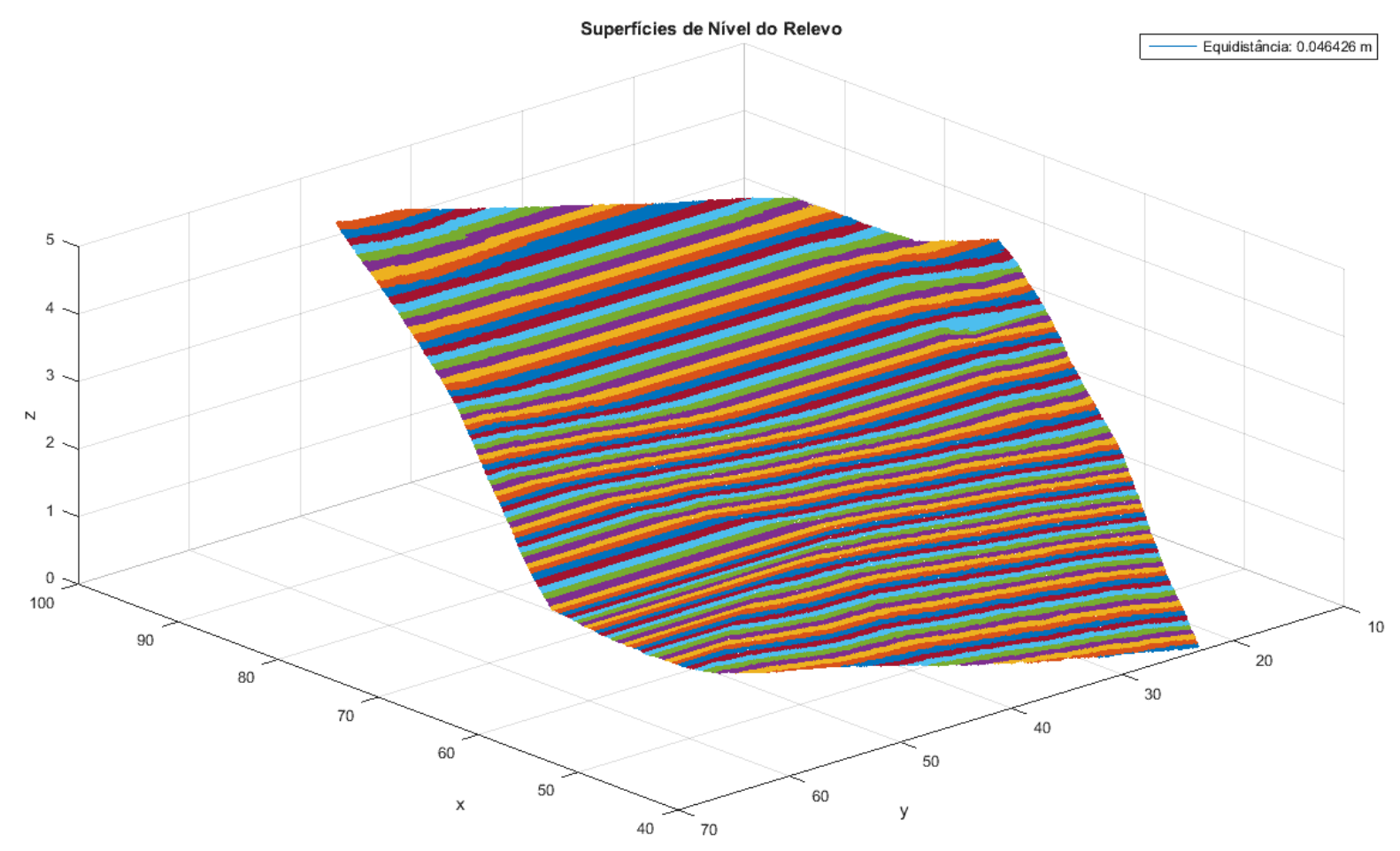

Fonte: O Autor.

RC: 58185

Disponível em: https://www.nucleodoconhecimento.com.br/matematica/volumes-e-linhas 
A Figura 7 ilustra as superfícies de nível em 10 faixas cuja equidistância é de 0,42627 $\mathrm{m}$ e na Figura 8 foram utilizada 100 faixas cuja equidistância é de 0,046426 m.

Uma aplicação importante do reconhecimento das curvas e superfícies de nível está na técnica de plantio em curvas de nível, a qual baseia-se no traçado de faixas com diferentes altitudes no terreno (ZONTA et al., 2012).

O reconhecimento das curvas de nível também é importante no cálculo do momento de transporte na movimentação de terra entre corte e aterro, além de também dar um perfil do terreno útil para o planejamento de dispositivos de drenagem em taludes de cortes e aterros ou na interseção do talude de aterro com o terreno natural e nas transições corte-aterro, o que pode evitar problemas de erosão, por exemplo.

Para o caso de linhas de fluxo de água no terreno, o cálculo é realizado a partir do gradiente em cada ponto do relevo, mais precisamente na direção oposta ao gradiente, pode ser realizado pela diferenciação parcial das equações (4) e (5), porém, nesse trabalho, optou-se em analisá-los a partir dos dados de relevo.

O gradiente foi calculado iterativamente a partir dos dados $(x, y, z)$ levantados com o drone, onde utiliza-se uma submatriz que contém em cada iteração nove coordenadas $(x, y, z)$, centrada em um ponto pivô $a_{i j}$ representando o valor de $z$ na respectiva posição $(x, y)$. O gradiente, a partir de do pivô $a_{i j}$, apontará na direção do máximo valor na vizinhança de $a_{i j}$ forma:

$$
\operatorname{grad}(z(x, y))=\max \left[\begin{array}{ccc}
a_{i+1 j-1} & a_{i+1 j} & a_{i+1 j+1} \\
a_{i j-1} & a_{i j} & a_{i j+1} \\
a_{i-1 j-1} & a_{i-1 j} & a_{i-1 j+1}
\end{array}\right]
$$

Caso o máximo valor da submatriz seja o próprio pivô, o gradiente será nulo, ou seja, a tangente em $a_{i j}$ é horizontal com ponto local de máximo indicando um espigão ou separador de águas ou ainda uma subsuperfície totalmente horizontal. A Figura 9 ilustra o resultado da equação (7) aplicado aos dados do relevo para os $(x-1, y-1)$ pontos, tem-se o seguinte campo gradiente: 
Figura 9 - Campo vetorial indicando o gradiente a partir de cada ponto $(x, y, z)$.

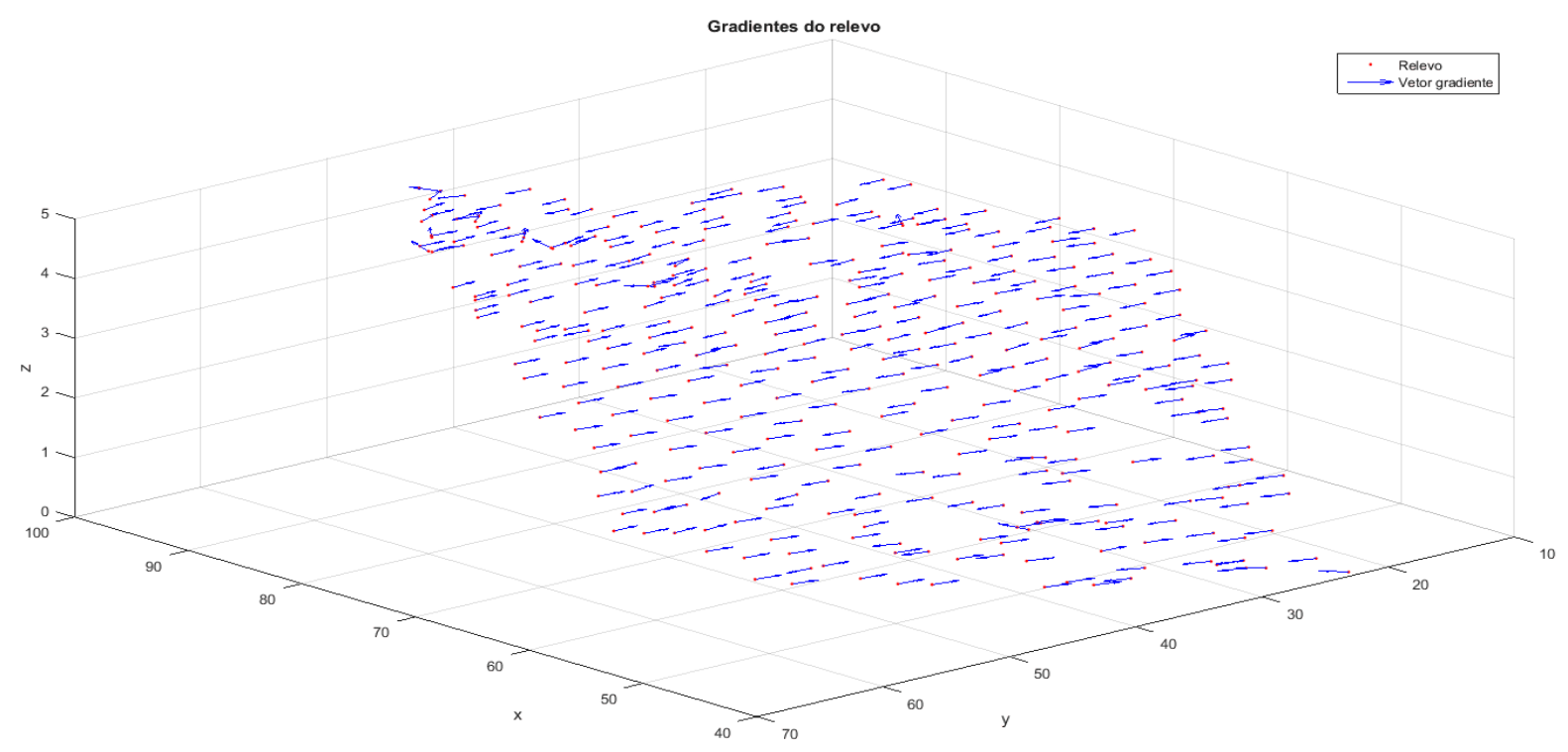

Fonte: O Autor.

A partir do campo de vetores gradiente obtém-se as linhas de fluxo de água no terreno, como ilustra a Figura 10.

Figura 10 - Campo vetorial indicando as linhas de fluxo (em verde) e os vetores na direção do fluxo (em azul).

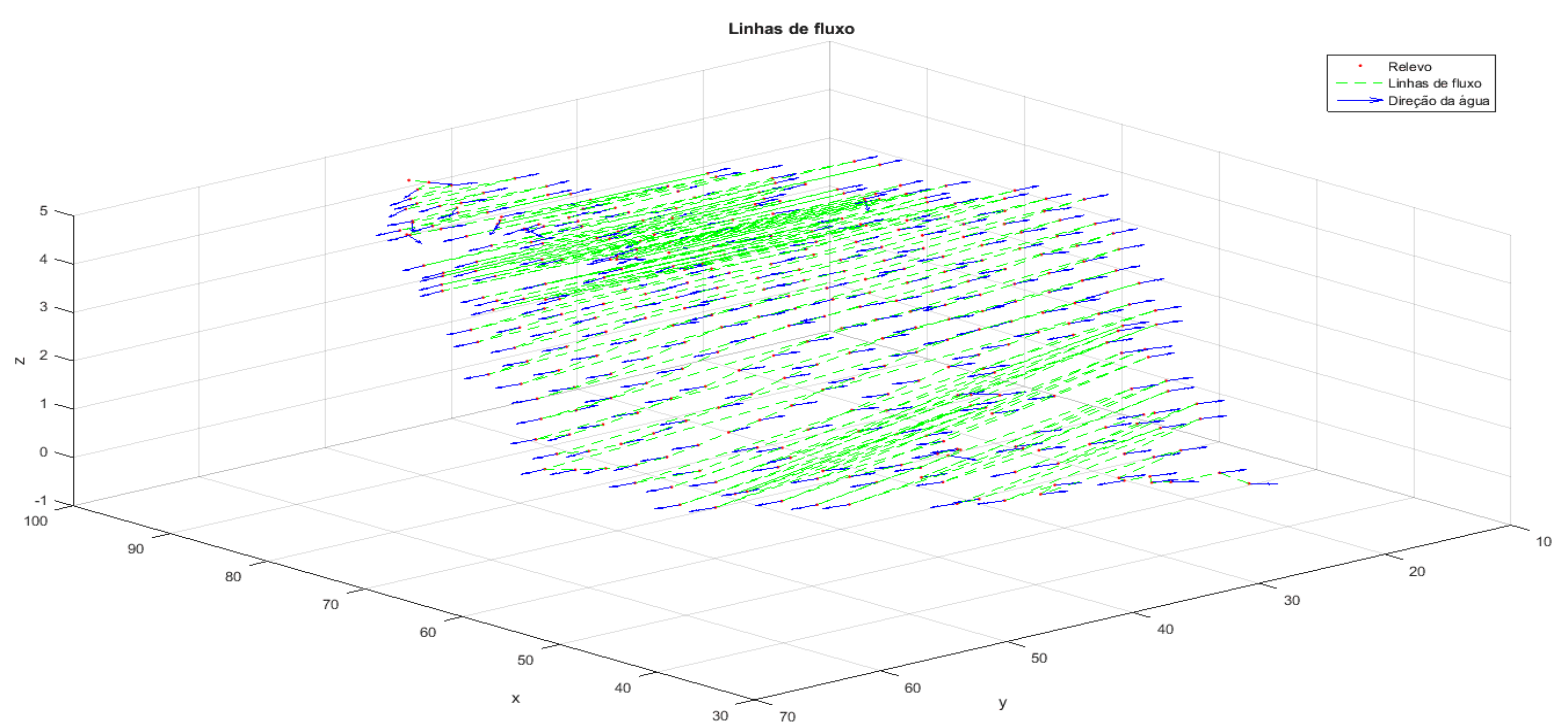

Fonte: O Autor.

RC: 58185

Disponível em: https://www.nucleodoconhecimento.com.br/matematica/volumes-e-linhas 
$\mathrm{Na}$ Figura 10 as linhas de fluxo e vetores de direção representam o caminho preferencial que a água de uma chuva densa percorreria sobre o terreno após a saturação deste. O reconhecimento de tais linhas pode permitir a quantificação e controle do movimento da água através do solo com vistas em proporcionar uma proteção contra os efeitos nocivos deste movimento, como a liquefação em fundos de valas, erosão, entre outros.

\section{CONSIDERAÇÕES FINAIS}

Os modelos matemáticos utilizados nesse trabalho apresentam-se como ferramentas computacionais alternativas para análise de dados de elevação e de terreno obtidos com o uso de drones.

Com o uso de regressão múltipla, linear e não linear, obteve-se precisão significativa para a estimativa de volumes de aterro para o caso testado.

Com o uso dos dados do relevo, pode-se descrever quantitativa e qualitativamente as curvas e superfícies de nível do terreno, cujo reconhecimento permite o planejamento para novas obras, seja na forma de terraços de plantio assim como de estruturas civis.

Ainda utilizando os dados do relevo, pode-se calcular o gradiente de cada ponto da superfície, com os quais, em sua direção oposta prevê-se o escoamento de água em caso de grande precipitação, por exemplo, mais uma vez, são informações adicionais para o engenheiro no planejamento de obras no terreno.

Por fim, destaca-se o potencial para o uso da metodologia desenvolvida com o uso de drones, porém, salienta-se que o uso de drone não substitui equipamentos como o GPS RTK e Estação Total, por exemplo, sendo essa metodologia complementar aos métodos tradicionais para tal fim. Em qualquer situação, é fundamental um estudo sobre a melhor estratégia para alcançar eficiência na execução de determinado serviço especializado de engenharia. 


\section{REFERÊNCIAS}

GARCIA, G. J.; PIEDADE, G. C. R. Topografia aplicada às ciências agrárias. Ed. 5, Nobel, São Paulo, 1984.

IRVINE, W. Surveying for construction. Ed. 5, McGraw-Hill, London, 2005.

OLIVEIRA, H. C.; JESUS, H. P. Análise comparativa de levantamentos planialtimétrico - topografia convencional, GPS e Drone, Monografia do Curso de Engenharia Civil, Escola de Engenharia Civil e Ambiental, Universidade Federal de Goiás, 2018.

PEDREIRA, W. J. P. Avaliação da Acurácia Altimétrica de Mapeamento Cartográfico Topográfico Usando VANT. Monografia do Curso de Bacharelado em Ciências Exatas e Tecnológicas, Universidade Federal do Recôncavo da Bahia, 2017.

VEIGA, L. A. K.; ZANETTI, M. A. Z.; FAGGION, L. F. Fundamentos de Topografia. Material didático do curso de Engenharia Cartográfica e de Agrimensura, Universidade Federal do Paraná, 2012.

ZONTA, J. H.; SOFIATTI, V.; COSTA, A. G. F.; SILVA, O. R. R. F.; BEZERRA, J. R. C.; SILVA, C. A. D. BELTRÃO, N. E. M.; ALVES, I.; FRANSCISO JÚNIOR, A. C.; CARTAXO, W. V.; RAMOS, E. N.; OLIVEIRA, M. C..; CUNHA, D. S.; MOTA, M. O. S.;SOARES, A. N.; BARBOSA, H. F. Práticas de Conservação de Solo e Água, Circular Técnica, EMBRAPA, 2012.

\section{APÊNDICE - REFERÊNCIA DE NOTA DE RODAPÉ}

2. Link para informações sobre 0 projeto Campus Map: http://www.campusmap.ufpr.br/

Enviado: Março, 2020.

Aprovado: Agosto, 2020. 